\title{
Simulation of the Recent Multidecadal Increase of Atlantic Hurricane Activity Using an 18-km-Grid Regional Model
}

Thomas R. Knutson

Joseph J. Sirutis

Stephen T. Garner

Isaac M. Held

Robert E. Tuleya

Old Dominion University

Follow this and additional works at: https://digitalcommons.odu.edu/ccpo_pubs

Part of the Atmospheric Sciences Commons, and the Meteorology Commons

\section{Repository Citation}

Knutson, Thomas R.; Sirutis, Joseph J.; Garner, Stephen T.; Held, Isaac M.; and Tuleya, Robert E., "Simulation of the Recent Multidecadal Increase of Atlantic Hurricane Activity Using an 18-km-Grid Regional Model" (2007). CCPO Publications. 239. https://digitalcommons.odu.edu/ccpo_pubs/239

\section{Original Publication Citation}

Knutson, T. R., Sirutis, J. J., Garner, S. T., Held, I. M., \& Tuleya, R. E. (2007). Simulation of the recent multidecadal increase of Atlantic hurricane activity using an 18-km-grid regional model. Bulletin of the American Meteorological Society, 88(10), 1549-1565.

doi:10.1175/bams-88-10-1549 


\title{
Simulation of the Recent Multidecadal Increase of Atlantic Hurricane Activity Using an 18-km-Grid Regional Model
}

\author{
by Thomas R. Knutson, Joseph J. Sirutis, Stephen T. Garner, Isaac M. Held, and Robert E. Tuleya
}

\begin{abstract}
A new $18-\mathrm{km}$-grid regional model successfully reproduces the observed multidecadal increase and interannual variations of Atlantic hurricane activity since 1980 , using large-scale interior nudging toward the NCEP reanalysis.
\end{abstract}

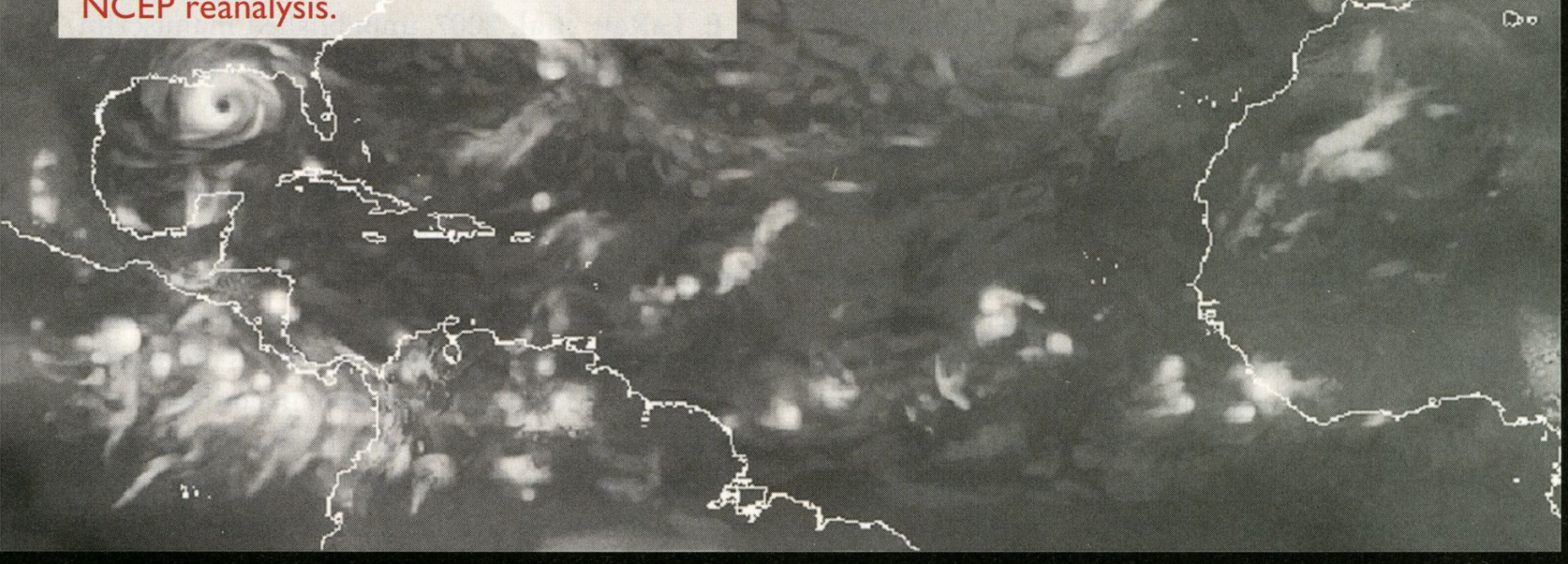

H urricane activity in the Atlantic basin increased markedly in the years 1995 2000 , compared with levels in the 1970 s and 1980s. For example, the accumulated cyclone energy (ACE) index in the Atlantic has been above the 1951-2000 median for all years from 1995 to 2005 except for the El Niño years

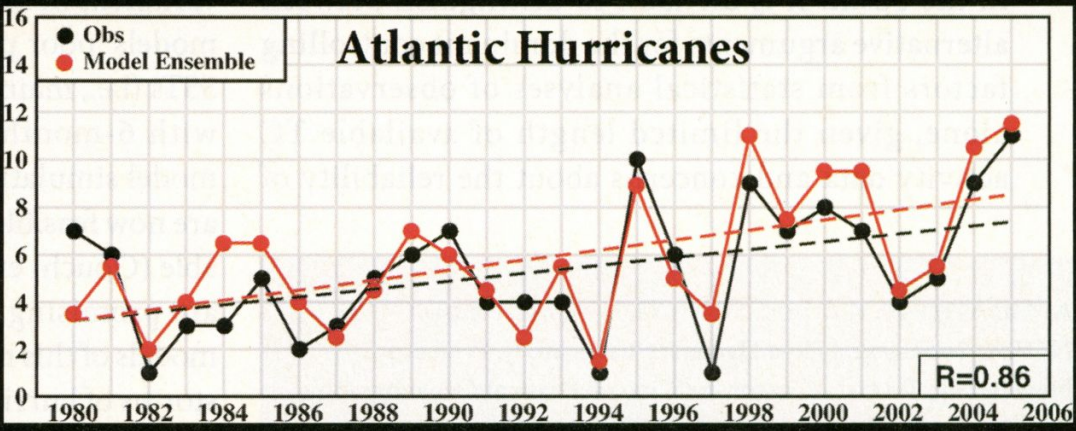
of 1997 and 2002 (e.g., Bell et al.

2006). The increase in activity since the early 1980 s has been confirmed using homogenized satellite-based records (Kossin et al. 2007). Two recent seasons (2004 and 2005) have been exceptionally active in terms of U.S. landfalling hurricanes (particularly for the Florida and the Gulf Coast regions), compared to typical activity levels in recent decades (Landsea 2005). In this report we introduce a new regional atmospheric model designed to simulate full seasons of tropical cyclone (TC) activity in the Atlantic. By testing the model against observed interannual variability and trends, we hope to

Top: model outgoing longwave radiation snapshot $\left(\mathrm{W} \mathrm{m}^{-2}\right)$ illustrating scales of disturbances. Bottom: annual number (Aug-Oct) of North Atlantic basin hurricanes (1980-2005). See figures 2 and 5 for more information. 
justify its use in advancing our understanding of the factors controlling Atlantic TC activity and the implications of this understanding for predicting changes in future TC activity in the basin. The main question addressed here is the following: Assuming one has essentially perfect knowledge of large-scale atmospheric conditions in the Atlantic over time, how well can one then simulate past variations in Atlantic hurricane activity using a dynamical model?

The cause of the recent upswing in Atlantic hurricane activity remains unresolved, with some investigators interpreting the increase as being the latest positive phase of a multidecadal cycle (e.g., Goldenberg et al. 2001), with a decrease in activity having occurred from the 1950s to the 1970s. This view implies an impending return to below-normal conditions at some point in the coming decades. Bell and Chelliah (2006) interpret the multidecadal fluctuations in Atlantic TC activity since the late 1940 s as resulting from a set of multidecadal modes related to tropical convection, although they are not specific about the origin of these modes. Others view the changes as part of a long-term rising trend due to anthropogenically forced global warming (e.g., Emanuel 2006; Mann and Emanuel 2006; Trenberth and Shea 2006), implying further growth of Atlantic hurricane activity in the future as a long-term climate warming trend continues in the twentyfirst century (Houghton et al. 2001). Determining whether the Atlantic hurricane changes in recent decades are part of a cycle, a long-term trend, or some combination of cycle and trend, is a crucial question for the future outlook of hurricane activity in the basin. It is difficult to distinguish between alternative arguments for the dominant controlling factors from statistical analyses of observations alone, given the limited length of available TC activity data and concerns about the reliability of

AFFiliations: KNUTSON, SiRUTIS, GaRner, AND HeLDNOAA/Geophysical Fluid Dynamics Laboratory, Princeton, New Jersey; TULEYA-Center for Coastal Physical Oceanography, Old Dominion University, Norfolk, Virginia

CORRESPONDING AUTHOR: Thomas R. Knutson, NOAA/ Geophysical Fluid Dynamics Laboratory, Forrestal Campus, Rt. I, Princeton, NJ 08542

E-mail: Tom.Knutson@noaa.gov

The abstract for this article can be found in this issue, following the table of contents

DOI: 10.1175/BAMS-88-10-1549

In final form 17 May 2007

C2007 American Meteorological Society historical TC data (Landsea et al. 2004; Landsea 2005; Landsea et al. 2006).

Dynamical simulations of Atlantic TC activity potentially provide model frameworks in which the factors controlling interannual variability and trends can be analyzed more directly. The resolutions of typical global climate models are often considered inadequate for meaningful simulations of TC activity, although Vitart and Anderson (2001) simulate a decrease in Atlantic tropical storms in the 1970s and 1980s, relative to the 1950s and 1960s, similar to that observed, using observed SSTs. More recently, Camargo et al. (2005) have shown that interannual variability of simulated tropical storm counts and (bias adjusted) accumulated cyclone energy in the Atlantic (and other basins) was significantly correlated with observations by using several low-resolution global atmospheric models forced with observed SSTs (see also McDonald et al. 2005; T. E. LaRow et al. 2007, unpublished manuscript). Vitart and Stockdale (2001) and Vitart (2006) have shown that current coupled models also have skill at predicting the interannual variability of tropical storm counts a season in advance in several basins, including the Atlantic, owing in part to the skill of the models in predicting the SSTs. The focus of these studies was on tropical storms, since the resolutions of the models were inadequate to address the question of the interdecadal modulation of major hurricanes, which is so prominently seen in the observations. Concerning interdecadal variability, Vitart (2006) finds that current coupled seasonal forecast models have difficulty simulating interdecadal tropical storm variations in the Atlantic, probably due to the coupled models' poor performance with predicting Atlantic SSTs (i.e., maintaining the interdecadal SST signals) with 6-month integrations. Global atmospheric model simulations with $\sim 20$ - to $30-\mathrm{km}$ grid spacing are now feasible on the largest supercomputers available (Oouchi et al. 2006; Bengtsson et al. 2007), and are promising tools for research in this area since models of this resolution appear capable of generating storms of hurricane strength. However, these models have not yet been used to address the question of recent Atlantic interannual/interdecadal variability and trends in TC or hurricane activity.

Our choice in this work is to utilize a new highresolution regional model covering the North Atlantic, which we anticipate may be useful for addressing some of the issues surrounding tropical Atlantic hurricane variations and trends. Specifically, in this preliminary study we examine the extent to which it is possible to simulate various aspects of 
Atlantic tropical storm and hurricane seasonal activity using a regional climate model forced on its boundaries by the observed atmospheric state, at the lower boundary by observed SSTs, and in the interior by relaxation toward the large-scale component of the time-varying atmospheric state. This framework should be thought of as an approach toward downscaling rather than prediction. In principle, this model can be forced with global coupled model simulations to study the response of Atlantic TC activity to anthropogenic increases in greenhouse gases, for example. The relevance of this framework for seasonal prediction would clearly depend on the relative importance and predictability of the different sources of large-scale information input into the model (SSTs, boundary conditions, and large-scale interior atmospheric state). Success in downscaling historical TC activity can be thought of as a prerequisite for meaningful predictions of TC activity using a regional nested model.

The section "Model description and experimental design" describes the basic model; "Simulation results" contains the main results from the experiments; and "Discussion" contains our concluding remarks. Some results from preliminary exploratory and tuning experiments and the procedure used for detecting and tracking storms are presented in two appendixes.

\section{MODEL DESCRIPTION AND EXPERI-} MENTAL DESIGN. The atmospheric model dynamical core used for this study is the Geophysical Fluid Dynamics Laboratory (GFDL) Regional Atmospheric Model (Pauluis and Garner 2006), which is compressible and nonhydrostatic. The model was run with specified observed SSTs [National
Centers for Environmental Prediction (NCEP-1 reanalysis; Kalnay et al. 1996)] over ocean points and was coupled to the GFDL land model version 2 (LM2) [based on the Land Dynamics Model of Milly and Shmakin (2002)] over land points. The land model predicts soil temperature and moisture fields and was run with five levels. The model domain covers the tropical and subtropical Atlantic, the Gulf of Mexico, and parts of western Africa (see Fig. 1). The model's $690 \times 300$ horizontal grid has a spacing of $1 / 6^{\circ}$ $(\sim 18 \mathrm{~km})$ and 45 unevenly spaced vertical levels, with the lowest model level at a height of $22 \mathrm{~m}$.

No cumulus parameterization is used in the primary runs. We made this choice because in preliminary experiments the model with no cumulus parameterization performed slightly better in this context than did a model version with a particular convection scheme activated, as briefly described in appendix A. Pauluis and Garner (2006) have 
studied the resolution dependence of nonrotating radiative-convective equilibrium in a doubly periodic domain with the identical model. They find some encouraging insensitivity of the largest convective cores to resolution, up to $16 \mathrm{~km}$. Since radiativeconvective equilibrium simulations should provide some information about the background random convective activity that generates seeds for cyclone development, these simulations prompted us to consider the no-parameterization option.

We use the five-species cloud microphysical scheme developed by Lin (Lin et al. 1983; Lord et al. 1984), coupled to the GFDL radiation package (GFDL Global Atmospheric Model Development Team 2004) assuming fixed height-dependent cloud particle sizes. Insolation is diurnally and seasonally varying. The boundary layer scheme is the level-2.5 turbulence closure of Mellor and Yamada (1982). The Monin-Obukhov similarity theory is used for the surface flux calculations, with an ocean roughness enhancement related to wind speed according to the scheme of Beljaars (1995).

The velocity, temperature, and humidity at all levels are nudged toward the NCEP-1 reanalysis (Kalnay et al. 1996) on a fast time scale (2 h) over a graduated $5^{\circ}$-wide band around the perimeter of the domain. The target data are time interpolated from the 6-hourly reanalysis data. In addition, in the interior of the model domain, zonal and meridional wavenumbers 0,1 , and 2 (of the model domain) at all levels were nudged toward similarly filtered reanalysis fields on a slower time scale (36-48 h). Through the nudging procedure, the model's solution is kept similar to the NCEP reanalysis on the large scale, while the model remains relatively unconstrained to generate smaller-scale disturbances within that solution. In that sense, we nudge toward a "perfect" large-scale solution and use the high-resolution model to provide added value by recovering information about smallerscale transient disturbances, such as hurricanes. The utility of the spectral nudging approach for regional climate downscaling has been demonstrated previously by several investigators (e.g., von Storch et al. 2000; Weisse et al. 2005; Miguez-Macho et al. 2005; Castro et al. 2005).

For this study, we assume that the NCEP-1 reanalysis adequately represents past variations in relevant large-scale atmospheric fields, including vertical profiles of temperature and humidity over the Atlantic. There is some evidence for remaining problems in radiosonde-based tropical tropospheric temperature trends (e.g., Santer et al. 2005), which could potentially affect the reanalyses and our model solutions. This remains a topic for future study as the reanalysis products are further refined.

Preliminary tests used to determine the nudging time scale for the simulations are discussed in appendix A. The specific nudging time scale (e.g., $36 \mathrm{~h}$ for Model2) was chosen to tune the model's performance in terms of basinwide tropical storm counts to approximate those observed for the 1982 and 1995 seasons. The development of two closely related versions of the model (Modell and Model2) is also described in appendix A. Modell was used to perform an initial set of 26 seasonal simulations (1980-2005), after which a code error was discovered. The code error was corrected and the model retuned (yielding Model2), followed by a rerun of all 26 seasons (along with 2006). Results presented in this study will demonstrate that the code error in Modell had little practical impact on the solutions (tropical cyclone metrics) in the context of this study. Therefore, in our judgment it is appropriate to include the Modell results as a second ensemble member in many of our analyses. ModelE will refer to the ensemble of results obtained from the Model1 and Model2 runs combined.

As discussed in appendix A, the storminess of the model is sensitive to the strength of the interior nudging, with stronger nudging reducing the number of storms. Further experiments, beyond the scope of the present study, are needed to understand this dependence in detail. Our preliminary hypothesisbased on our experiences with this model as well as with several previous models-is that the regional model run without nudging generates a vertical mean thermodynamic profile that is too unstable; therefore, a primary role of the nudging is to correct this mean profile. It is possible that without interior nudging a convective parameterization would be required at this model resolution to prevent excessive storm development.

The experiments described here are initialized on 0000 UTC 29 July of each season, and integrated through the end of October. For the 2005 and 2006 seasons, the integrations began on 29 May and ended on 31 December to explore the early and late season activity. For a small subset of years (e.g., 1982, 1995, etc.), two or more ensemble members were completed for a given model (Model1 or Model2). The additional ensemble members were created by repeating the runs but starting the integration one or two days earlier than the standard start date of 29 July. While an ensemble size larger than 2 is highly desirable, the expense of running additional ensemble members was prohibitive in this exploratory study. 
The first model data analyzed by the tropical storm detection program are generally 0600 UTC 31 July, allowing for about a 2-day model spinup period prior to the main analysis period. The 6 -hourly output from these runs was analyzed to objectively identify the occurrence of tropical storms and hurricanes in the model. The storm identification and tracking procedure is presented in detail in appendix B. We then compare the TC statistics of the model to the observed statistics (number, location, track, intensity) of Atlantic tropical cyclones as obtained from the National Hurricane Center hurricane database (HURDAT; online at www.aoml.noaa.gov/hrd/hurdat/Data_Storm.html).

\section{SIMULATION RESULTS.}

Long-term means and aggregate storm statistics. In Fig. 1, the time-mean precipitation climatology (August-October) from the Model2 simulations (1980-2006) is compared with the observations from the Global Precipitation Climatology Project (GPCP; online at http://cics.umd. edu/ yin/GPCP/main.html). Precipitation is only indirectly constrained by the interior and boundary nudging of the model, so that a comparison of simulated versus observed precipitation is a meaningful measure of model performance. The model produces an Atlantic intertropical convergence zone (ITCZ) similar in shape and magnitude to the observed ITCZ, although the model's ITCZ is slightly too confined toward the equator. The precipitation storm track along the U.S. east coast is also relatively well produced in terms of position and magnitude. In the extreme eastern Pacific, the model produces substantially more rainfall than observed. The model pre- cipitation is suppressed near the lateral boundaries, in large part because of the strong nudging of the humidity toward reanalysis. This cautions against placing too much emphasis on any model features located near the domain boundaries. Many largescale fields such as atmospheric temperatures, wind, and moisture are not compared here, because these are nudged toward the reanalysis on large spatial
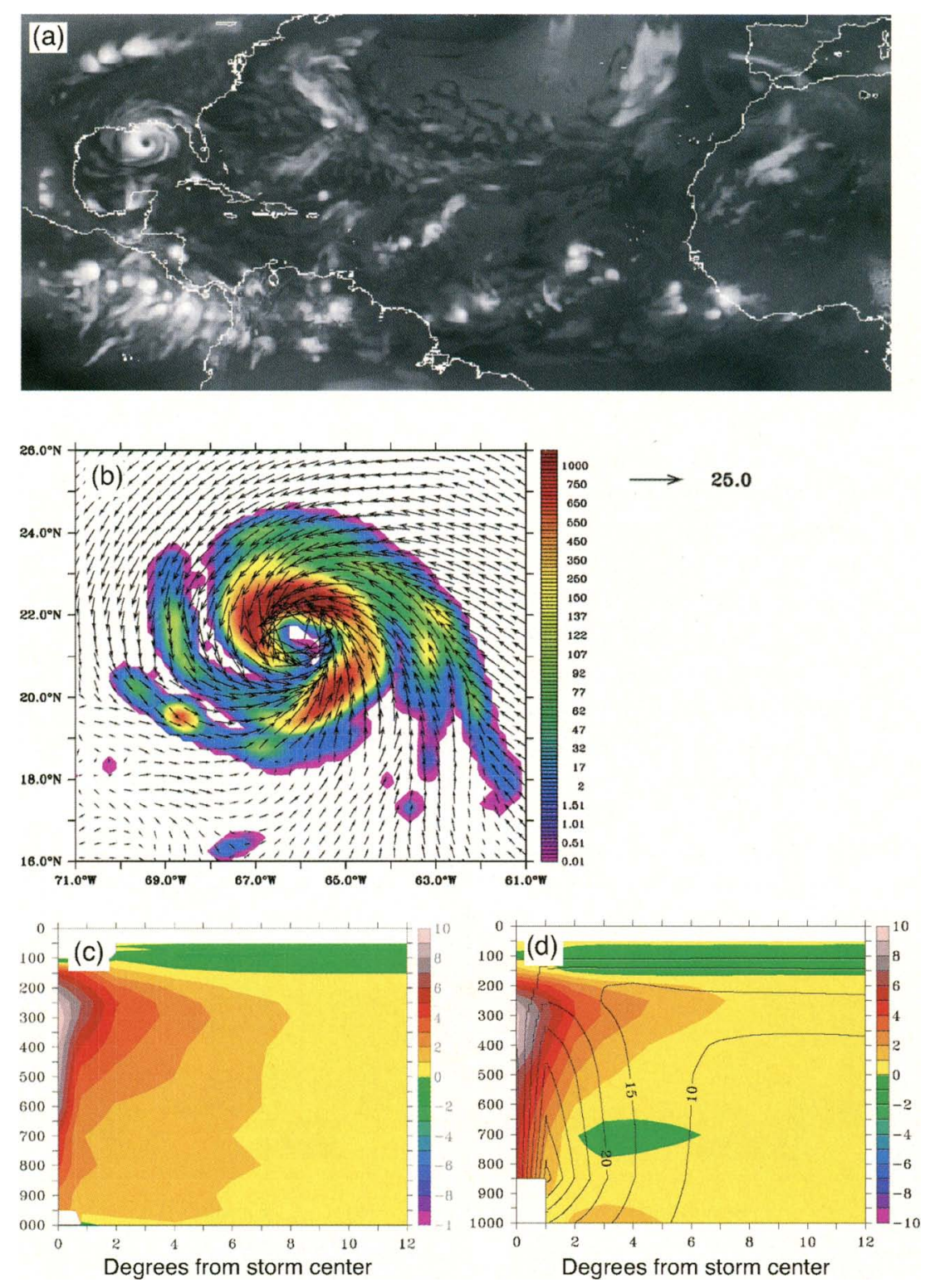

Fig. 2. Sample hurricane fields from the model: (a) model outgoing longwave radiation snapshot $\left(\mathrm{W} \mathrm{m}^{-2}\right)$ illustrating scales of disturbances; (b) rainfall rate $\left(\mathrm{mm} \mathrm{day}^{-1}\right)$ and surface wind vectors, with reference $25 \mathbf{~ m ~ s}^{-1}$ vector shown beside the diagram for a sample model hurricane; and (c) observed composite temperature anomaly for steady-state typhoon (adapted from Frank 1977); (d) model hurricane composite temperature anomaly (shading) and wind speeds (contours). The model composite is an axisymmetric average for all hurricane periods simulated by Modell and Model 2 combined. 
scales, and the model's climatology thus remains close to the reanalysis.

Model fields for a sample hurricane and a composite hurricane from the Model2 simulations are shown in Fig. 2. For the sample storm in Fig. 2b, the rain-rate field from the model hurricane includes features resembling rainbands surrounding the storm, along with a clearly discernible eye at the storm center. The outgoing longwave radiation field snapshot in Fig. 2a also shows a well-defined eye in a hurricane approaching the Gulf Coast, and in addition qualitatively illustrates various scales of tropical convective activity in the model. The temperature anomaly field for a storm-centered composite of all Modell and Model2 hurricane periods (Fig. 2d) shows a warm core with a maximum magnitude of about $10^{\circ} \mathrm{C}$ at $\sim 300 \mathrm{hPa}$, in good agreement with the observed composite for western Pacific typhoons by Frank (1977), as reproduced in Fig. 2c. The model's composite wind speed is a maximum at about the 850-hPa level, in agreement with Frank's typhoon composite (not shown). In terms of horizontal scale, the model's 850 - $\mathrm{hPa}$ wind speed maximizes at a distance of about $1^{\circ}$ from the storm center, indicating a somewhat larger simulated radius of maximum winds than is typically observed in Atlantic hurricanes ( $65 \mathrm{~km}$, per Kimball and Mulekar 2004).

The asterisks in Fig. 1 show observed and simulated (Model2) locations of all (August-October) tropical storm formations for 1980-2006. The general formation regions and densities appear to be fairly well captured to first order in the simulations. Figure 3 shows maps of tropical storm formation and occurrence, and of hurricane occurrence during the 27-yr simulation period. The tropical storm formation maps (cf. Figs. 3a,d) show fairly realistic simulation rates in the Atlantic main development region $\left(10^{\circ}-20^{\circ} \mathrm{N}\right)$ and the Gulf of Mexico, with excessive formation rates off the U.S. east coast. Tropical storm occurrence rates (cf. Figs. 3b,c) are again fairly realistic in the main development region, but are somewhat too high particularly from $20^{\circ}$ to $40^{\circ} \mathrm{N}$. Hurricane occurrence rates are too low in the main development region and somewhat too high in the northern part of the domain, so that the "center of mass" of hurricane occurrence is shifted poleward in the model compared with observations. Both the model and observations show some areas of relatively infrequent tropical storm formation in parts of the Caribbean, compared with the Gulf of Mexico and the main development region (e.g., see gray/white shading in Figs. 3a,d indicating $<1$ storm per decade during the period).

Table 1 presents regionally accumulated statistics, including tropical storm origins and hurricane and tropical storm occurrence days and their correlations with the observed time series. Statistics for some measures are presented separately for the regions north and south of $30^{\circ} \mathrm{N}$. The analysis shows that there is a positive bias in hurricane days, tropical storm days, and tropical storm origins, with the bias especially pronounced for tropical storm days and origins north of $30^{\circ} \mathrm{N}$. Interestingly, the correlations of tropical

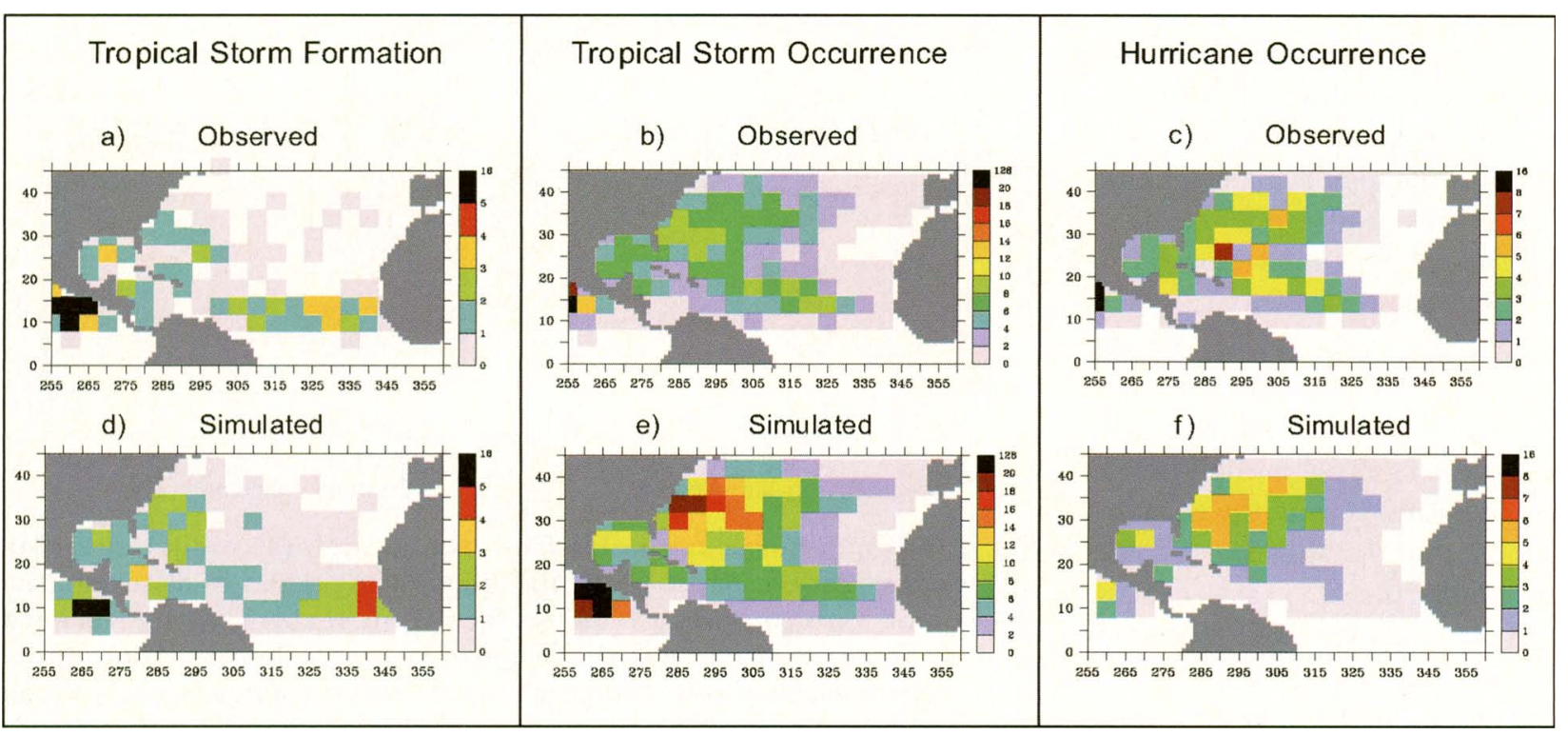

FIG. 3. Maps of observed geographical distribution (1980-2006) of (a) tropical storm formation, (b) tropical storm occurrence, and (c) hurricane occurrence in units of storms per decade within $4^{\circ}$ latitude $\times 5^{\circ}$ longitude grid boxes. (d), (e), (f) Simulated distributions for the model ensemble (ModelE). 
TABLE I. Means and correlation coefficients for various hurricane $(H)$ and tropical storm (TS) measures. The correlations are for the period 1980-2005 for Modell, 1980-2006 for Model2, and 1980-2005 for the model ensemble (ModE = avg of Modell and Model2). Corr2 is the correlation coefficient of linearly detrended data. Units of means: ACE $\left(10^{4} \mathrm{kt}^{2}\right)$, PDI $10^{9} \mathrm{~m}^{3} \mathrm{~s}^{-2}$, and mean maximum wind $\left(\mathrm{m} \mathrm{s}^{-1}\right)$.

\begin{tabular}{|c|c|c|c|c|c|c|c|c|c|}
\hline & $\begin{array}{c}\text { Mean } \\
\text { Obs }\end{array}$ & $\begin{array}{l}\text { Mean } \\
\text { Modl }\end{array}$ & $\begin{array}{l}\text { Mean } \\
\text { Mod2 }\end{array}$ & $\begin{array}{l}\text { Corr } \\
\text { ModI }\end{array}$ & $\begin{array}{l}\text { Corr } \\
\text { Mod2 }\end{array}$ & $\begin{array}{l}\text { Corr } \\
\text { ModE }\end{array}$ & $\begin{array}{l}\text { Corr2 } \\
\text { Modl }\end{array}$ & $\begin{array}{l}\text { Corr2 } \\
\text { Mod2 }\end{array}$ & $\begin{array}{l}\text { Corr2 } \\
\text { ModE }\end{array}$ \\
\hline No. of $\mathrm{H}$ & 5.30 & 5.79 & 6.09 & 0.76 & 0.74 & 0.86 & 0.68 & 0.68 & 0.82 \\
\hline No. of TS & 9.00 & 11.52 & 11.30 & 0.60 & 0.72 & 0.74 & 0.42 & 0.63 & 0.63 \\
\hline $\mathrm{ACE}$ & 107.6 & 101.44 & 108.35 & 0.72 & 0.66 & 0.76 & 0.58 & 0.52 & 0.64 \\
\hline PDI & 261.7 & 206.70 & 225.18 & 0.70 & 0.60 & 0.72 & 0.55 & 0.44 & 0.58 \\
\hline Mean max wind & 38.74 & 33.36 & 33.91 & -0.01 & 0.20 & 0.13 & -0.08 & 0.18 & 0.08 \\
\hline U.S. land TS & 2.37 & 2.00 & 2.25 & 0.36 & 0.51 & 0.57 & 0.24 & 0.36 & 0.43 \\
\hline U.S. land $\mathrm{H}$ & 1.04 & 0.48 & 0.96 & 0.30 & 0.32 & 0.41 & 0.21 & 0.25 & 0.27 \\
\hline Major H & 2.59 & 0.96 & 1.33 & 0.64 & 0.54 & 0.70 & 0.44 & 0.37 & 0.52 \\
\hline $\mathrm{H}$ days north of $30^{\circ} \mathrm{N}$ & 8.19 & 7.10 & 10.07 & 0.40 & 0.51 & 0.48 & 0.31 & 0.42 & 0.41 \\
\hline $\mathrm{H}$ days south of $30^{\circ} \mathrm{N}$ & 13.88 & 8.65 & 11.43 & 0.61 & 0.51 & 0.64 & 0.48 & 0.40 & 0.53 \\
\hline $\mathrm{H}$ days east of $70^{\circ} \mathrm{W}$ & 15.33 & 11.34 & 15.83 & 0.56 & 0.42 & 0.52 & 0.50 & 0.33 & 0.44 \\
\hline $\mathrm{H}$ days west of $70^{\circ} \mathrm{W}$ & 6.74 & 4.41 & 7.07 & 0.22 & 0.46 & 0.56 & 0.01 & 0.36 & 0.40 \\
\hline TS origin north of $30^{\circ}$ & 0.96 & 2.19 & 1.86 & 0.06 & 0.05 & 0.09 & 0.07 & 0.11 & 0.12 \\
\hline TS origin south of $30^{\circ}$ & 8.07 & 9.33 & 9.83 & 0.72 & 0.72 & 0.78 & 0.57 & 0.63 & 0.68 \\
\hline TS origin east of $70^{\circ}$ & 6.04 & 7.25 & 7.77 & 0.52 & 0.63 & 0.62 & 0.36 & 0.54 & 0.51 \\
\hline TS origin west of $70^{\circ}$ & 3.00 & 4.27 & 3.92 & 0.36 & 0.43 & 0.50 & 0.25 & 0.37 & 0.44 \\
\hline TS days north of $30^{\circ} \mathrm{N}$ & 18.28 & 30.98 & 32.30 & 0.49 & 0.62 & 0.64 & 0.41 & 0.57 & 0.58 \\
\hline TS days south of $30^{\circ} \mathrm{N}$ & 32.17 & 47.68 & 50.49 & 0.64 & 0.61 & 0.70 & 0.49 & 0.50 & 0.58 \\
\hline TS days east of $70^{\circ} \mathrm{W}$ & 34.25 & 55.58 & 57.84 & 0.51 & 0.62 & 0.63 & 0.40 & 0.54 & 0.55 \\
\hline TS days west of $70^{\circ} \mathrm{W}$ & 16.19 & 23.08 & 26.29 & 0.45 & 0.57 & 0.66 & 0.30 & 0.50 & 0.59 \\
\hline
\end{tabular}

storm days and hurricane days versus observations for the region north of $30^{\circ} \mathrm{N}$ are fairly reasonable. However, the correlation of tropical storm origins versus observations in the region north of $30^{\circ} \mathrm{N}$ is negligible, indicating that the excessive numbers of tropical storms forming north of $30^{\circ} \mathrm{N}$ are apparently spurious storm developments.

The intensities of the simulated and observed storms are summarized in a wind-pressure scatterplot in Fig. 4. The model simulates hurricanes into the Saffir-Simpson category-3 range (i.e., $964-945 \mathrm{hPa}$ ) and occasionally to category 4 ( $<945 \mathrm{mb}$ ) in terms of central pressure, but only into the category- 2 range (43-49 $\left.\mathrm{m} \mathrm{s}^{-1}\right)$ in terms of maximum surface wind speed. The most intense storm simulated by the model

Fig. 4. Scatterplot of maximum surface wind speed $\left(\mathrm{m} \mathrm{s}^{-1}\right)$ versus minimum central surface pressure $(\mathrm{h} \mathrm{Pa})$ for observed (black) and simulated (red = Modell; blue $=$ Model2) Atlantic TCs (1980-2006). Modell data are for 1980-2005. Solid lines are least squares quadratic best-fit lines to the points. reached a central pressure of about $937 \mathrm{hPa}$, with maximum surface winds of about $47 \mathrm{~m} \mathrm{~s}^{-1}$ (Fig. 4). In comparison, observed central pressures in the Atlantic basin have reached as low as $882 \mathrm{hPa}$ (Wilma in 2005), and maximum surface wind speeds as high as $85 \mathrm{~m} \mathrm{~s}^{-1}$ (Camille in 1969). The wind-pressure relationship in the model (e.g., yellow line in Fig. 4)

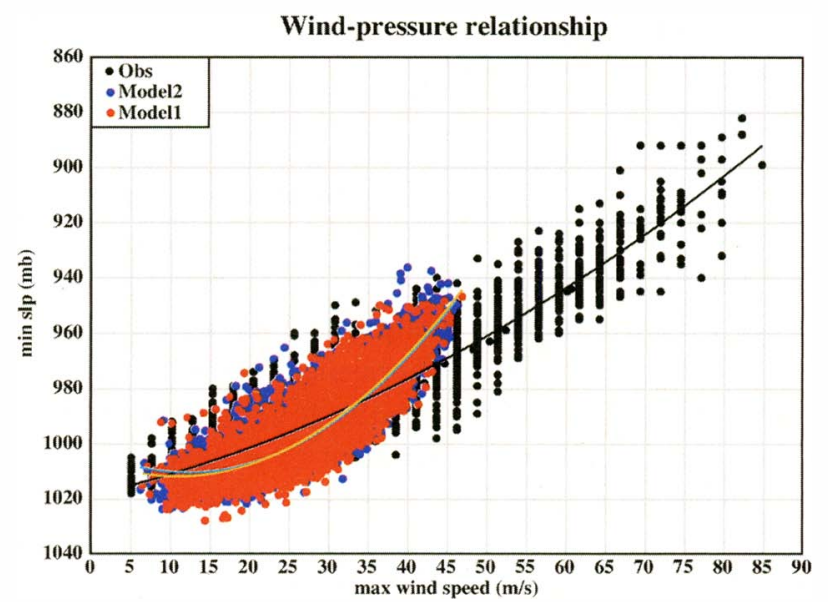


is substantially less linear than in the observations, as various model deficiencies act to progressively suppress wind intensities, for given central pressures, beginning at values exceeding about $25 \mathrm{~m} \mathrm{~s}^{-1}$. This wind-pressure relationship deficiency in the model is likely at least in part due to the observed decrease in surface drag at high wind conditions, an effect that is being addressed with new surface flux parameterizations (e.g., Moon et al. 2007). In that study, Moon et al. attempt to explain physically why reduced drag coefficients affect surface wind speeds more than central pressures in simulated hurricanes. Another potential factor behind our model's deficient intensities is the still somewhat limited horizontal resolution (18-km grid) used at present. However, in previous work (e.g., Knutson et al. 1998) we have shown that the GFDL hurricane model (at a similar resolution) produces storms with substantially lower minimum pressures and higher near-surface wind speeds than the regional model used in the present study (e.g., Fig. 4). This reinforces the notion that factors other than resolution may well play a role in our current model's deficiencies. In short, the various potential causes of the weak intensities and wind-pressure relationship deficiencies in our model are still under investigation.

Owing to the greater model bias for wind speeds compared with central pressure, we have chosen to use central pressures where possible in assessing simulated storm intensities. For example, in determining the category of hurricane in the model, we use central pressure criteria, and for computation of the cyclone energy and power dissipation indexes later in this section, we use wind speeds inferred from central pressures according to the relationship used in Landsea (1993), which is based on Kraft (1961). However, for determining whether a storm has reached tropical storm or minimal (category 1 ) hurricane strength, we used the original lowest-modellevel wind speed obtained from the model without further adjustment.

Interannual variability and trends in TC activity. Time series of annual hurricane counts for observations and the model ensemble (ModelE) simulations for the 26 (August-October) seasons from 1980 to 2005 are shown in Fig. 5, along with least squares linear trend lines. The correspondence between the simulated and observed variability and trends is striking, with a correlation coefficient $(r)$ of 0.86 (i.e., $74 \%$ of variance reproduced), which is the highest correlation found in the study. Shown in Fig. 6 are hurricane count indexes (Fig. 6d) for the individual models (Model1 and Model2) and observations, along with several other indexes of tropical storm and hurricane activity.

Correlations between observed time series and those from the individual models as well as the model ensemble (ModelE) are presented in Table 1, based on both detrended and nondetrended data. The hurricane count correlations for Model 1 and Model 2 are about 0.75 . For most measures in Table 1, the correlation for the ensemble (ModelE) exceeds that of both individual models. Aside from hurricane counts, notably high ensemble correlations are evident for the ACE (Fig. 6a; $r=0.76$ ), the power dissipation index (PDI; Fig. 6b; $r=0.72$ ); and tropical storm frequency (Fig. $6 f ; r=0.74$ ). Smaller though still substantial ensemble correlations are found for U.S. landfalling tropical storms (Fig. 6c; $r=0.57$ ) and basinwide major hurricane counts (Fig. 6e; $r=0.70$ ). For basinwide major hurricane counts, the model has a notable low bias (e.g., Table 1; Fig. 6e). Simulated variations in U.S. landfalling hurricanes (Fig. $6 \mathrm{~g}$ ) are correlated with observations at only $r=0.41$. Annual mean maximum TC intensities are essentially uncorrelated between model and observations ( $6 \mathrm{~h} ; r=0.13)$.

These results, particularly for basinwide hurricane counts, tropical storm counts, ACE, and PDI, demonstrate that the model has substantial skill at reproducing seasonal basinwide statistics of hurricane and tropical storm activity provided that the large-scale environment remains close to that observed. The smaller correlations for the various U.S. landfalling activity measures are not unexpected, because it is likely to be less difficult to simulate realistic genesis rates for the entire basin than to accurately simulate U.S. landfalling activity, given the smaller number of cases in the latter and the strong dependence of U.S. landfall on details of the atmospheric steering flow anomalies and storm trajectories.

In terms of linear trends over the period ${ }^{1}$ (dashed lines in Figs. 5 and 6), the model-simulated trends are generally in broad agreement with those observed, showing pronounced increases for all metrics except the annual mean maximum TC intensity, which increases only slightly for both the model and observations. The model substantially underpredicts the magnitude of the observed trend in major hurricane counts (Fig. 6e). The rising trend in PDI (Fig. 6b) and U.S. landfalling tropical storms and hurricanes

\footnotetext{
${ }^{1}$ Note that a linear trend is used to describe the secular changes over the analysis period, but this is not meant to imply that the trend is sustained outside of the period in question (see the introduction).
} 
(Figs. 6c,g) is slightly underpredicted. The model slightly overpredicts the observed trend in tropical storm frequency (Fig. 6f). Trend magnitudes for the other metrics are fairly well simulated. The trend lines and Table 1 illustrate that the model has relatively modest biases in most of the metrics examined, although it has a clear positive bias in tropical storm counts (Fig. 6f) and a clear negative bias in annual mean maximum TC intensity (Fig. 6h) and major hurricane counts (Fig. 6e).

Close examination of some of the time series in Fig. 6 [e.g., ACE (Fig. 6a), PDI (Fig. 6b), major hurricane counts (Fig. 6e)] indicates that the observed time series has a more abrupt transition around 1995 from low to high values than is simulated in the model, where the change appears to be more gradual over time. In the case of ACE (Fig. 6a) the model is in relatively good overall agreement with observations, except for underprediction of the single year 1995. For hurricane counts (Fig. 5), ModelE reproduces the observed temporal behavior very well in almost all aspects, and the agreement for the $\sim 1995$ transition

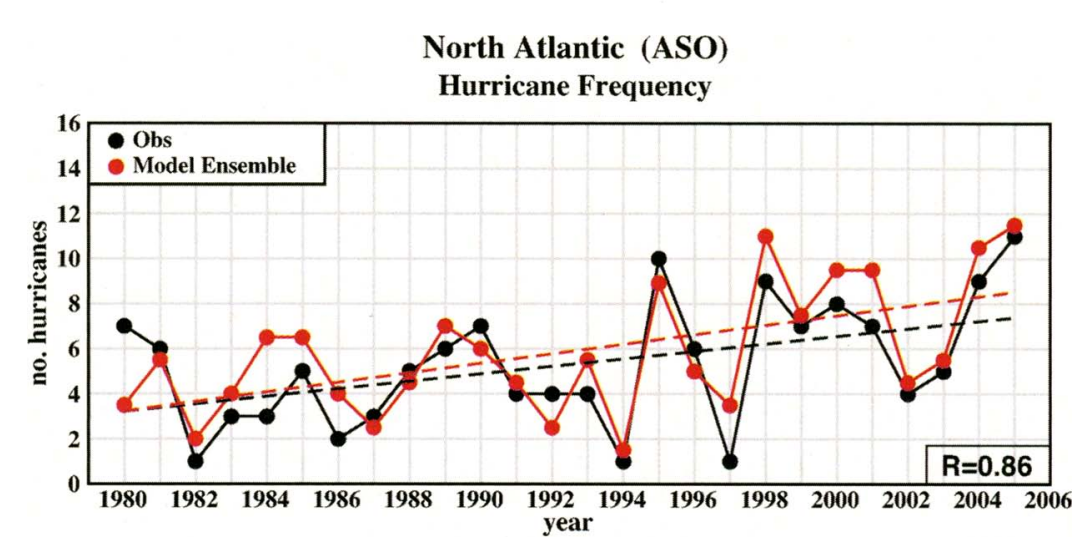

Fig. 5. Annual number (Aug-Oct) of North Atlantic basin hurricanes (1980-2005). Results are shown for observations (black) and model simulations (red $=$ ModelE, the ensemble mean of Modell and Model2 experiments) for all Aug-Oct seasons, excluding 2006 (for which a Modell experiment is not available). Least squares best-fit linear trends are depicted by the dashed lines.
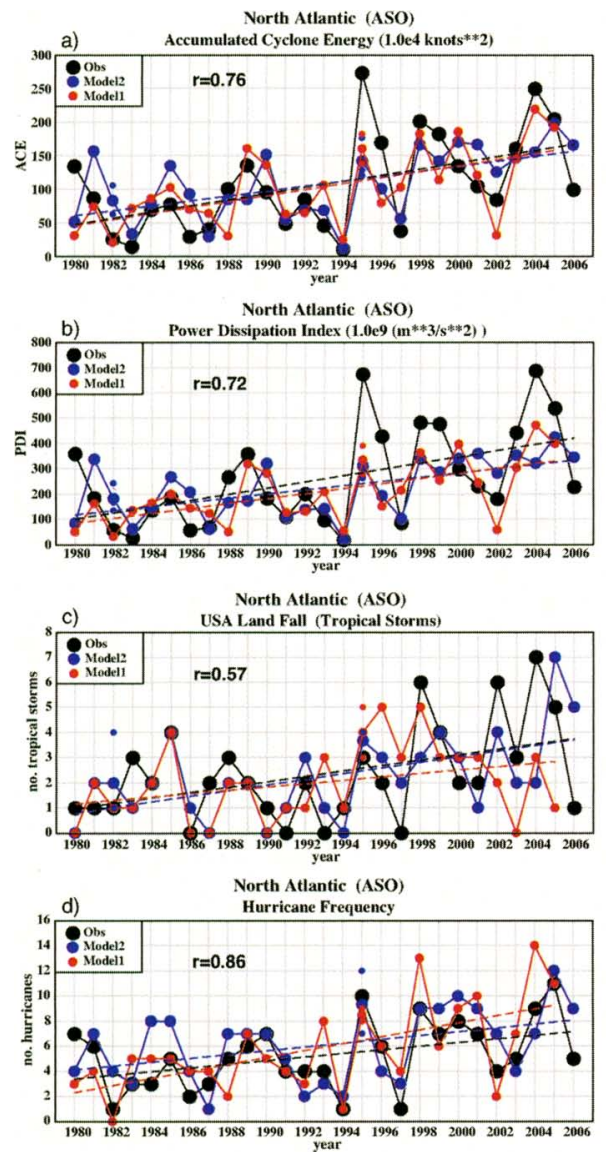

Fig. 6. Annual number or index value (Aug-Oct) of North Atlantic basin: (a) ACE $\left(10^{4} \mathrm{kt}^{2}\right)$, (b) PDI $\left(10^{9} \mathrm{~m}^{3} \mathrm{~s}^{-2}\right)$, (c) U.S. landfalling tropical storms, (d) basinwide hurricane count, (e) number of major hurricanes (categories 3-5), (f) basinwide tropical storm count, (g) U.S. landfalling hurricanes, and (h) annual mean maximum surface wind speed averaged across all TCs $\left(\mathrm{m} \mathrm{s}^{-1}\right)$. Results are shown for observations (black) and model simulations (red) for all Aug-Oct seasons during 1980-2006 (1980-2005 for Modell). Least squares best-fit linear trends are depicted by the dashed lines in each diagram. Small red and blue dots denote individual ensemble members which have been combined, where available, to form a composite result (larger red and blue circles) for that model and year. 
is also relatively good for tropical storm frequency (Fig. 6g).

Tropical cyclone track maps for each individual year (Model2 and observed) are presented in Fig. 7. The narrow lines without circles represent tracks of storms that are above minimal tropical storm intensity but below hurricane intensity; circles depict hurricane intensity, and colors of the circles depict the Saffir-Simpson category of the storm. Scanning over the results, one can readily find examples of seasons where the model has not performed well. For example, the model clearly overpredicts activity in the El Niño year of 1982 and in 1986. The unrealistic concentration of tracks along the northern edge of the domain (e.g., 1995a, 1998, and 2004) is apparently an artifact of storms nearing the northern boundary of the model. Despite these problems, the success of the model at capturing important differences between years is encouraging. The overall character of the tracks for many individual seasons is fairly well reproduced in the model. As expected from the earlier analysis of activity measures such as ACE (Fig. 6a; Table 1), the model is fairly skillful at distinguishing unusually active seasons (e.g., 1995, 2004, and 2005) from unusually quiet seasons (e.g., 1983, 1987, 1994). [The observed ACE index for 1995 (August-October) exceeded that for 2004 and 2005 and is underpredicted by the model, as shown in

FIG. 7 (THIS PAGE AND NEXT). Tropical cyclone tracks and intensities for observations and Model2 simulations (Aug-Oct season) for (a) 1980-93 and (b) 1994-2006. Circles indicate times when storms were of at least hurricane strength; color shading in the circles denotes Saffir-Simpson category intensity, based on central pressure criteria (see the legend). For 1995, three ensemble members of Model2 are shown (1995a, 1995b, 1995c), with 1995b grouped in the "observed" column for convenience.

a) Observed
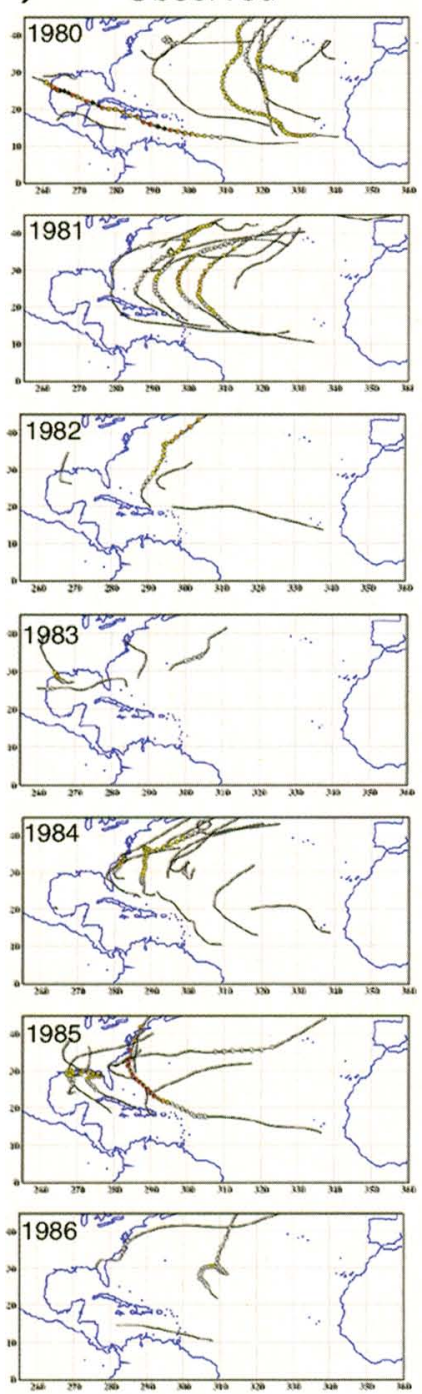
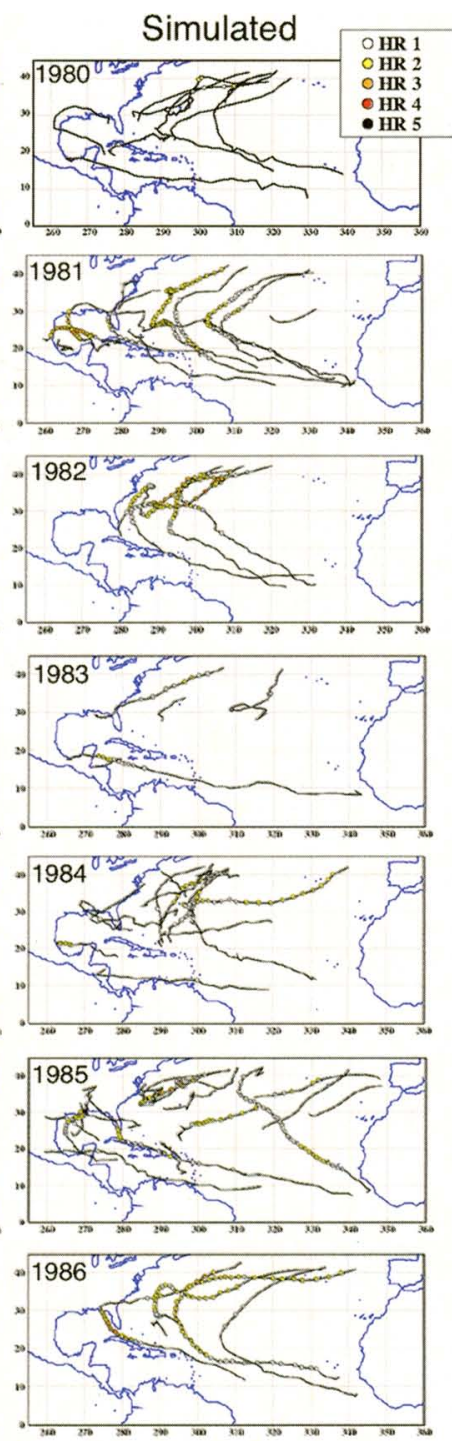
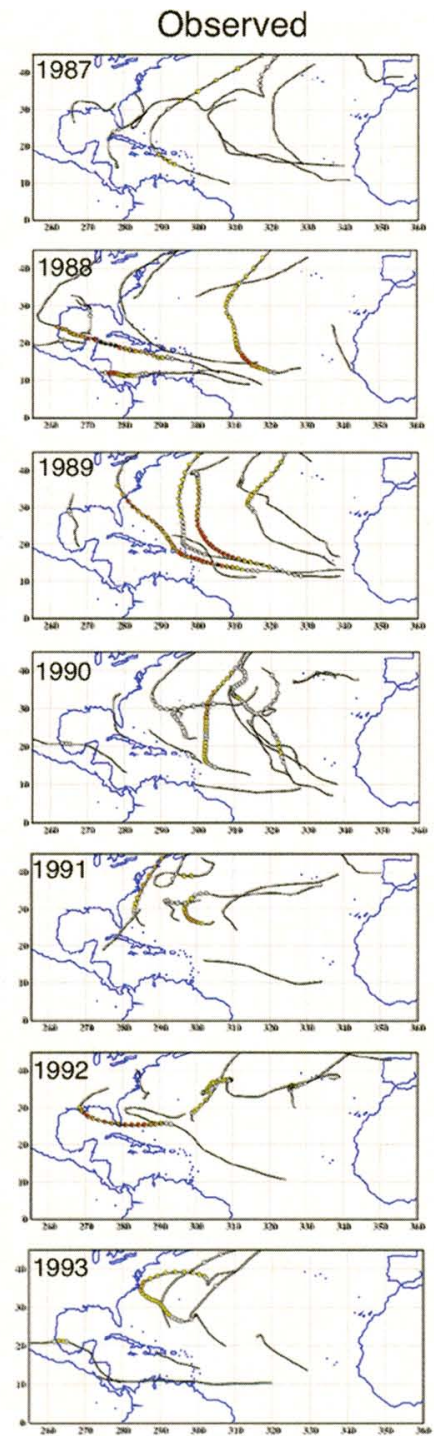
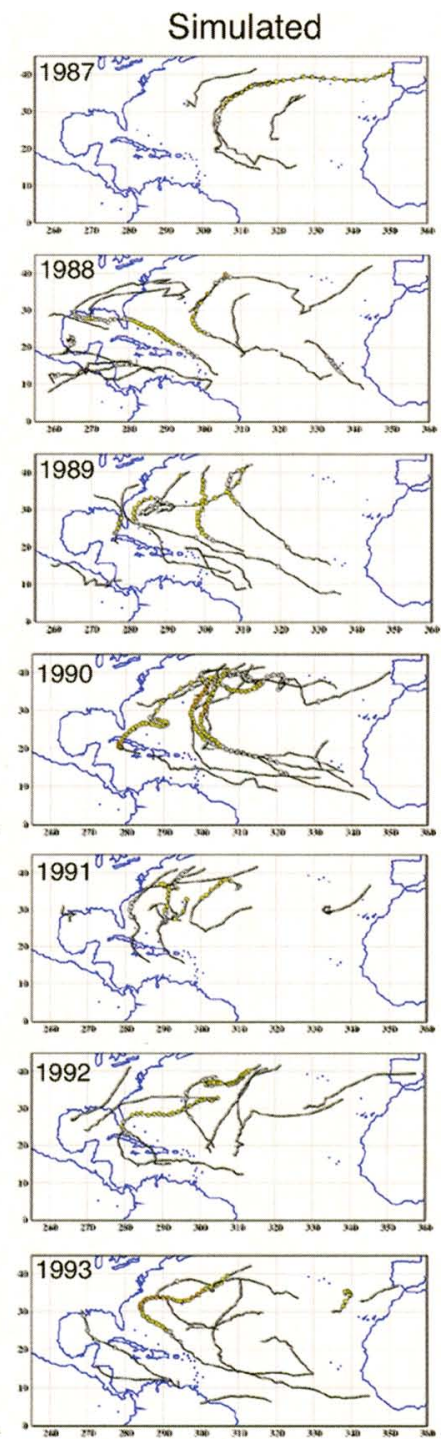
Fig. 6a.] The model clearly simulates a generally more active era of basinwide tropical cyclones in the years from 1995 on, compared to the years preceding 1995, consistent with the results shown in Fig. 6.

On the subbasin scale, a notable shortcoming is the failure of both the Model2 run (Fig. 7b) and the Modell run (not shown) to reproduce the unusually high activity observed for Florida in 2004. Concerning the unusually high Gulf of Mexico activity observed in 2005, the single Model 2 run does simulate unusually high activity (Fig. 7b), whereas the single Modell run does not (not shown). As noted earlier, the model has comparatively less skill at simulating past variations in U.S. landfalling TCs than basinwide TC activity (Fig. 6e; Table 1). Whether this decrease in model skill for smaller-scale (but economically important) regions, relative to the skill on the basinwide level, is due to model deficiencies or to the inherent stochastic nature of events on these scales-even when constraining the large-scale flow and thermal structure-is unclear.

The response of the model's Atlantic tropical storm and hurricane frequency to ENSO variability is examined in Fig. 8. The observations show that fewer tropical storms and hurricanes form during El Niño years than during La Niña or neutral years. Both Model1 and Model2 reproduce this overall tendency. For hurricanes (Fig. 8b) the percentage reduction during El Niño years is less in Modell than in the observations, whereas the cold year versus warm year percentage contrast is fairly realistic in Model2. The overall positive bias in tropical storm frequency in the model is evident in Fig. 8a, whereas a slight positive overall bias in hurricane frequency is evident for Model 2 in Fig. 8 b. The results indicate that the model successfully reproduces the observed aggregate ENSO-related variations of tropical storm and hurricane frequency for the study period. b)
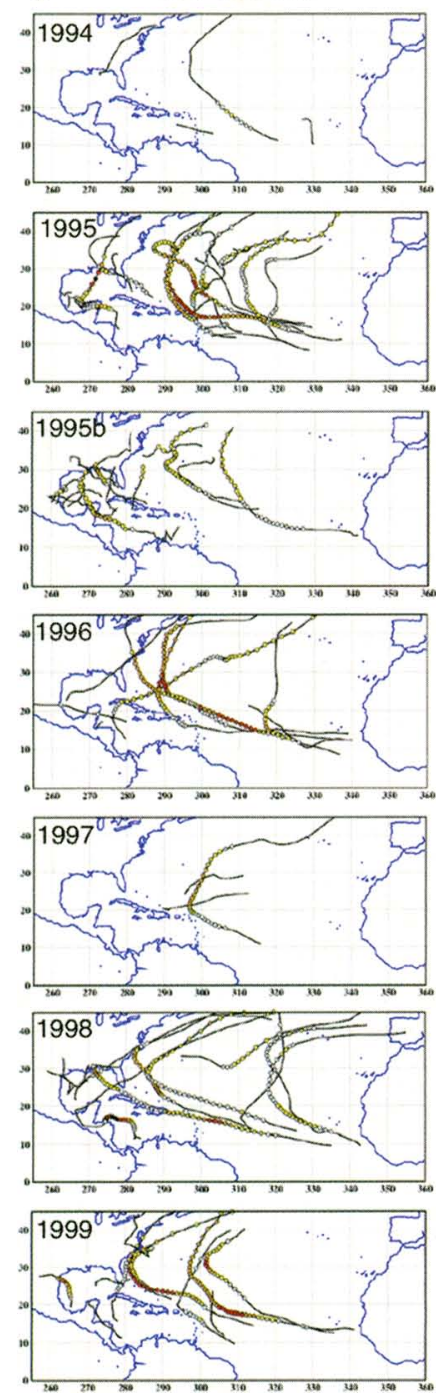

Simulated
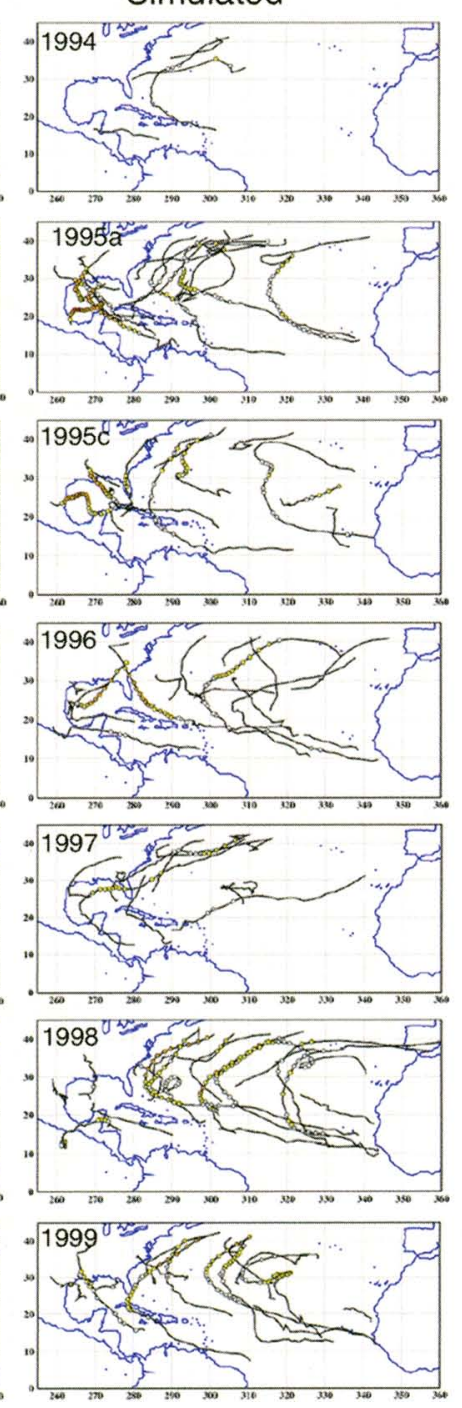
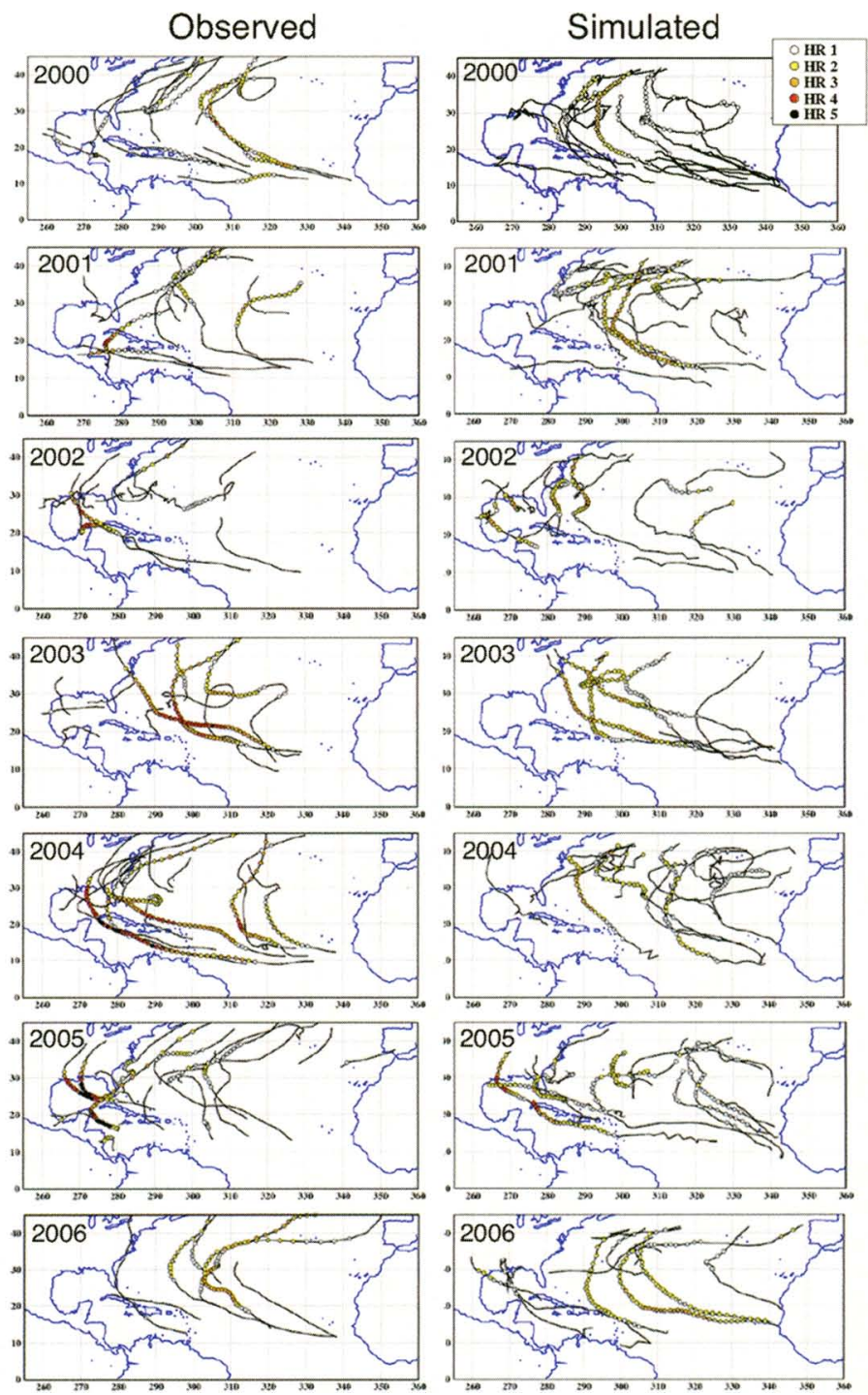
A final test shown (for Model2) is a comparison of the contrasting 2005 and 2006 seasons. For these two years, the Model2 simulations were begun two months earlier than our usual start date (i.e., on 29 May) and ended two months later (i.e., on 31 December), so that the months of June, July, November, and December were also simulated. These four months had high activity in 2005 but not in 2006. Figure 9 compares both the dates of tropical storm formations and the maximum intensities of observed and simulated tropical cyclones for the 2005 (Figs. 9a,b) and 2006 (Figs. 9c,d) seasons. The results show that the model realistically simulates the relatively active early season in 2005 and the relatively inactive early season of 2006 . The model also realistically shuts down the 2006 season in the latter part of September. An unrealistic feature of the 2006 simulation is the excessive activity, particularly of weaker storms, during the active period from late July to mid-September. The overprediction of hurricanes for August-October 2006 is 9 (simulated) versus 5 (observed), as shown in Fig. 6d. Thus, the model is successful at distin-
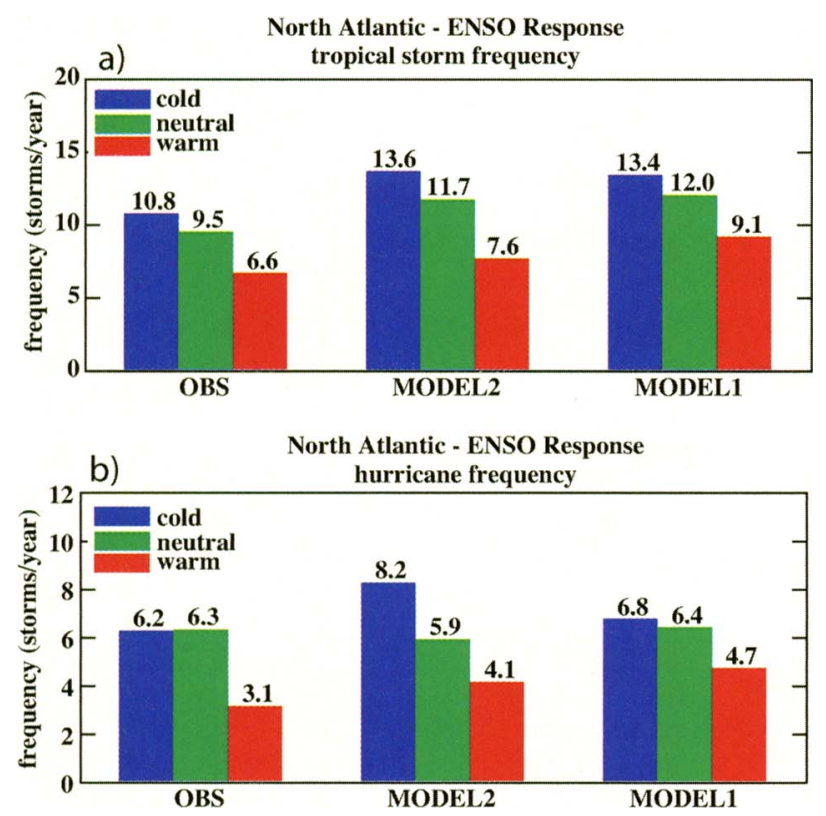

Fig. 8. Frequency of occurrence of (a) tropical storms and (b) hurricanes during EI Niño warm events (red), ENSO neutral seasons (green), and La Niña cold events (blue). Results are shown for observations and simulations (Modell and Model2) for 1980-2005. El Niño years include 1982, 1986, 1987, 1991, 1994, 1997, 2002, and 2004. La Niña years include 1983, 1984, 1985, 1988, 1995, 1998, 1999, and 2000. Remaining years are "neutral." Year classification is available online at www. cpc.ncep.noaa.gov/products/analysis_monitoring/ ensostuff/ensoyears.shtml. guishing some important characteristics of the contrasting 2005 and 2006 seasons, although the simulated activity during the 2006 core season was excessive.

DISCUSSION. These results indicate that the regional model, using specified SSTs and interior nudging toward the observed large-scale atmospheric conditions, reproduces the secular increase in Atlantic hurricane activity during 1980-2006. It also captures several aspects of the higher-frequency interannual variability, such as the relation of Atlantic tropical storm and hurricane counts to ENSO.

These results raise several important questions. Through what mechanisms does the model derive its simulation skill? What mechanisms are most important in the model for producing the observed increase in Atlantic TC activity in recent years?

The hindcast downscaling skill shown in Fig. 5 for the ensemble model (ModelE) is striking. One could question whether the hurricane occurrences are somehow being wired into the solution by the large-scale nudging. In that regard, it is important to note the differences in detail of the simulations in cases where more than one ensemble member is available (e.g., 1995 in Fig. 7b). There are also a number of cases evident in Figs. 7 and 9 where the simulated hurricanes occur in a different part of the basin, or at different times during the season, in the model versus the observations. For example, for the 1995 results in Fig. 7, hurricane formation occurs more frequently in the main development region in the observations compared to the model. For all of these reasons, we can conclude that individual genesis events are not directly forced by the interior nudging, but rather that the model is able to recover information about genesis statistics (and other measures of hurricane activity) based on specification of large-scale forcing factors alone.

As briefly described in the introduction, it is difficult to address the issue of physical mechanisms (e.g., shear versus thermodynamics) using statistical analyses of observations alone. Both dynamical (e.g., vertical shear; Goldenberg et al. 2001) and thermodynamical (e.g., potential intensity and SST; Emanuel 2005a,b; 2006) measures are well correlated with the trends and variations in TC activity, and in fact these environmental measures also tend to be well correlated with each other. Much longer records of Atlantic TC activity would be invaluable for this purpose. For example, Mann and Emanuel's (2006) finding of a century-scale rising trend in Atlantic TC counts, similar to the warming trend in SSTs in the basin, 
could be an important indication that Atlantic TC activity is increasing due to greenhouse gas-induced warming. However, the reliability of basinwide Atlantic TC statistics prior to the 1940s is a matter of contention (e.g., Landsea 2005; C. W. Landsea 2006, personal communication). Moreover, the lack of reliable records of vertical wind shear and atmospheric lapse rates extending back over the entire twentieth century hinders assessment of their relative roles in any such century-scale changes.

The TC regional modeling framework introduced here may provide another means of addressing these questions. It should be possible to determine the relative importance of changes in vertical shear and in the mean thermodynamic profile, at least in the case of the model results. As a next step, we intend to assess whether realistic simulations of Atlantic TC activity can be produced by embedding our regional model within a global atmospheric model running over observed SSTs. To the extent that this is successful, one could then compare how Atlantic TC behavior is affected by very broad-scale SST warming (essentially uniform through the Tropics and subtropics) versus how it is affected by more localized Atlantic SST warming, such as that believed to occur during transitions to the warm phase of the Atlantic multidecadal oscillation or perhaps in response to reduced aerosol forcing over the Atlantic.

CONCLUSIONS. We have simulated 27 Atlantic hurricane seasons (August-October, 1980-2006) using a new regional nested model, which is forced

c) Observed

d) Simulated

\section{5}
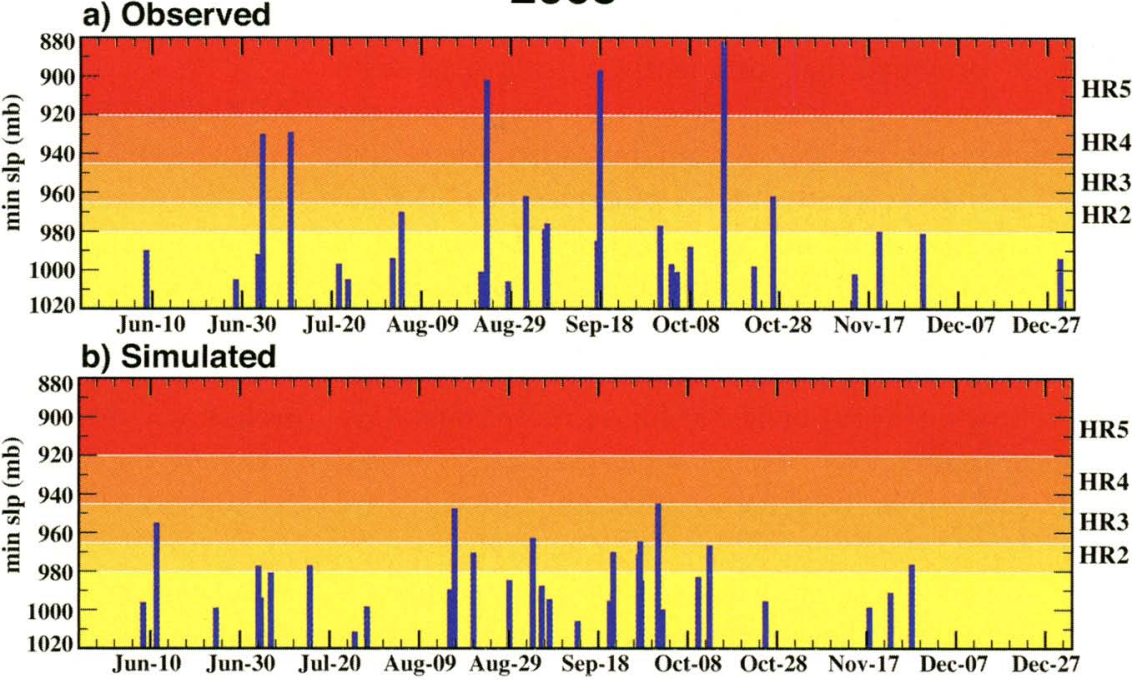

2006
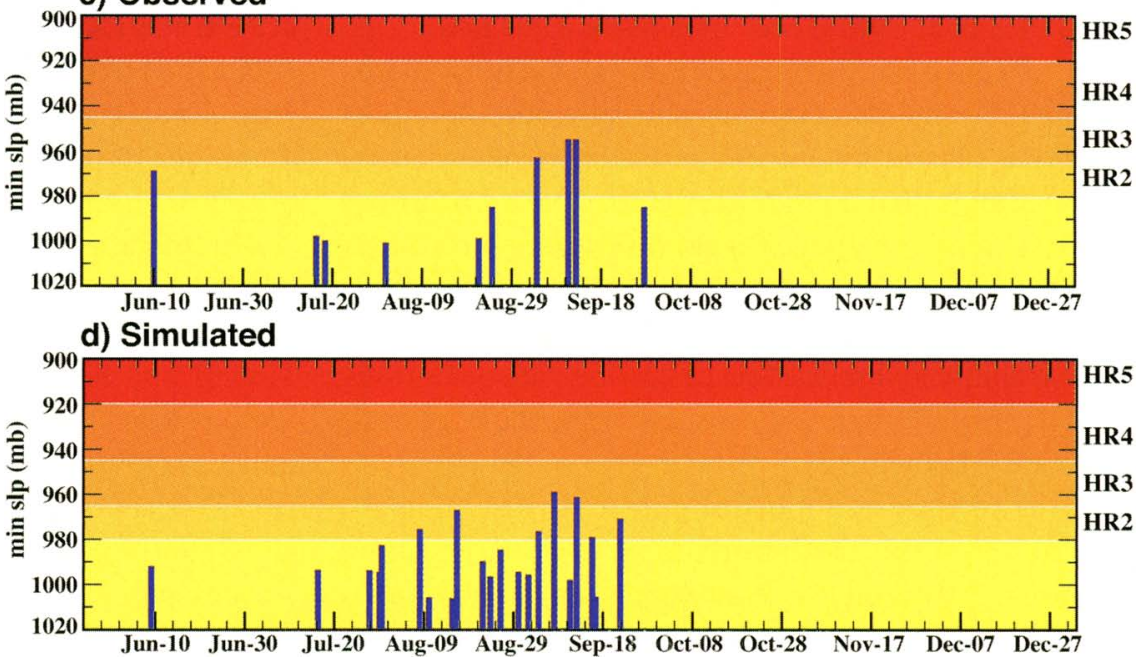

Fig. 9. Comparison of times of tropical storm formations and maximum intensities of observed and simulated (Model2) tropical cyclones for the (a), (b) 2005 and (c), (d) 2006 seasons. Each bar is located on the horizontal axis at the time the storm first reached tropical storm strength. The height of each bar depicts the maximum intensity attained during each storm's lifetime (in terms of minimum central pressure). Color shading and the labels HR2-HR5 along the right vertical axis denote the Saffir-Simpson hurricane intensity categories 2-5.

on the boundaries and nudged on the largest interior spatial scales toward NCEP reanalysis. This model demonstrates an ability to produce basinwide hurricane statistics such as hurricane counts, ACE, and PDI that agree remarkably well with observed variations, including the trend toward increasing activity over the period 1980-2005 as well as other interannual variations. In addition, observed statistical relations of Atlantic tropical storm and hurricane frequency versus ENSO are well captured in the model. We 
conclude that this model demonstrates significant skill in simulating such hurricane-related statistics-provided that sufficiently reliable large-scale atmospheric conditions are available for nudging the model on large scales. Within this constrained largescale framework, the model generates smaller-scale transients, including tropical storms and hurricanes up to category 4 , having several basinwide statistical properties similar to those observed.

Some of the subregional details and even the basinwide storm behavior for some seasons have clear shortcomings. For example, the model's overall tropical storm frequency is too high, and there are spurious storm developments, uncorrelated with observed genesis statistics, particularly in subtropical latitudes. The current model also generally fails to produce higher-intensity hurricanes (i.e., category 5), even in terms of central pressures, and the model's wind-pressure relationship becomes increasingly deficient at central pressures below $\sim 990 \mathrm{hPa}$.

Regarding our experimental design, a twomember model ensemble generally does not allow for a season-by-season assessment of potential predictability, as in Vitart et al. (1997). However, by simulating 26 (27) separate seasons for Model1 (Model2), we have obtained a large enough sample for a preliminary assessment of our model's overall capability for hindcasting basinwide statistics on hurricanes and tropical storms, assuming the large-scale state is known.

There are a number of potentially useful applications of this framework, to be explored in future work. For example, preliminary work is under way to use the model to assess the relative roles of dynamical (e.g., vertical shear) and thermodynamical (e.g., potential intensity) factors in the recent increase of Atlantic hurricane activity. We also plan to attempt simulations of pre-1980 Atlantic TC activity to see whether the model can reproduce either the reported variations in hurricane activity since the 1950s (e.g., Landsea 2005) or the reported century-scale rising trend in Atlantic TC counts (e.g., Mann and Emanuel 2006). The model might also be useful in the case of the tropical Northwest Pacific, where there are significant discrepancies between different assessments of TC-related trends since the mid-1960s (e.g., Emanuel 2005a; Knaff and Sampson 2006). The impact of greenhouse gas-induced climate warming on future Atlantic hurricane activity is another important topic currently being explored. In general, the reliability of future TC projections, and of retrospective simulations of twentieth-century TC activity, will crucially depend on obtaining reliable large-scale atmospheric and SST conditions from sources external to this model.

ACKNOWLEDGMENTS. We acknowledge the efforts of Isidoro Orlanski and Brian Gross in the early development of the nonhydrostatic regional model, and Oliver Pauluis for more recent development work. We thank three anonymous reviewers for their comments-Sergey Malyshev for providing spinup land surface initial conditions for each year of our experiments; Chris Kerr for technical assistance with the computational environments for the code; and GFDL Director Ants Leetmaa for support and encouragement of this project. NCEP reanalysis 1 data were provided by the NOAA/OAR/ESRL PSD, Boulder, Colorado, from their Web site at www.cdc. noaa.gov/. Significant computational resources for these experiments were provided through the NASA Columbia Supercomputing Project.

\section{APPENDIX A: MODEL TUNING AND PRELIMINARYIAUXILIARY EXPERIMENTS.}

Our experimental design was adopted based on a number of preliminary experiments, which are briefly described in this section.

Due to the large computational expense of running all 26-27 seasons, the full set of runs was completed only for the models with the "final settings" (i.e., Model1 and Model2) as discussed below. For most preliminary experiments described here, generally only one (1995) or two (1995 and 1982) seasons were run. This approach was chosen so that highly active (1995) and very inactive (1982) Atlantic hurricane seasons could be compared and to indicate whether the model was reasonably simulating both the average level of TC activity and some important aspects of its interannual variability.

The results for the preliminary experiments are summarized in Table 2 in terms of seasonal tropical storm counts. In the experiments with no interior (spectral) nudging, the model produces too many tropical storms. There is also evidence for too little contrast between the active and inactive seasons $(1982$ and 1995). A set of auxiliary experiments was done using a cumulus convection parameterization-the relaxed Arakawa-Schubert (RAS) scheme (Moorthi and Suarez 1992), using settings similar to those for the GFDL Atmospheric Model version 2 (AM2) global model (GFDL Global Atmospheric Model Development Team 2004). In the RAS experiments, the mean level of TC activity in our model is fairly realistic, without interior nudging, but there appears to be too little contrast between the active and inactive seasons (although further experiments would 
be needed to confirm this). Without cumulus parameterization, but with interior (spectral) nudging of large-scale winds, temperature, and moisture applied at all levels using a 2-h time scale, a strong contrast between the 1982 and 1995 seasonal counts emerges, although there is too little storm activity overall. This is slightly improved upon in a 12 -h nudging run, where there is a better relative contrast between the 1982 and 1995 seasons, but still too little activity overall. With nudging $(12 \mathrm{~h})$ of winds only, the model reverts to a much too active tropical storm regime with little contrast evident between the 1982 and 1995 seasons.

We note, in passing, the preliminary suggestion based on this experiment that the forcing of interior circulation features is of less importance to our results than the forcing of the mean thermodynamic state. The final settings, used for our Modell experiments, consists of 48-h interior (spectral) nudging of winds, temperature, and moisture at all levels, and yields a fairly realistic contrast between 1982 and 1995, and also a fairly realistic mean level of TS counts for those years.

After completing the initial series of 26 Model1 runs, we discovered a code error in the spectral nudging routine that affected the target fields below about $1000 \mathrm{~m}$ above sea level. The error resulted in target surface fields for the interior spectral nudging being generally too warm and moist. We reran the 1982 and 1995 years with this error fixed and found that the tropical storm counts reproduce the observations most closely provided that the nudging time scale is decreased slightly from $48 \mathrm{~h}$ to 24 or $36 \mathrm{~h}$ (Table 2). We therefore reran all 26 seasons as well as the additional 2006 season using the bug-corrected model with the $36-\mathrm{h}$ nudging time scale. This is referred to as Model2.

These preliminary experiments demonstrate that the model's TC activity is sensitive to the details of the large-scale interior nudging, including what variables are nudged, and the time scale of the nudging. The final settings chosen, based on the model's performance as shown in Table 2, could likely be further improved upon with additional tuning. There are also likely to be other sensitivities, such as the vertical structure of the nudging, the number of horizontal wavenumbers included in the nudging, the model parameterizations, etc., but these were not analyzed for the present study. The strength of the interior nudging is clearly an important optimization parameter in this model.

\section{APPENDIX B: TROPICAL CYCLONE DETECTIONANDTRACKING ALGORITHM.}

The following algorithm was used to objectively identify the occurrence of tropical storms and hurricanes in the model. The scheme is adapted from earlier work by Vitart et al. $(1997,2003)$ with some modifications for use with our higher-resolution, higher-frequency model data.

Potential storm identification. Using 6-hourly data, points in space and time satisfying the following conditions are located:

1) A local relative vorticity maximum at $850 \mathrm{hPa}$ exceeds $1.6 \times 10^{-4} \mathrm{~s}^{-1}$.

2) The surface pressure increases by at least $4 \mathrm{hPa}$ from the storm center within a radius of $5^{\circ}$. The 
closest local minimum in sea level pressure, within a distance of $2^{\circ}$ latitude or longitude from the vorticity maximum, is defined as the center of the storm.

3) The distance of the warm-core center from the storm center does not exceed $2^{\circ}$. The temperature decreases by at least $0.8^{\circ} \mathrm{C}$ in all directions from the warm-core center within a distance of $5^{\circ}$. The closest local maximum in temperature averaged between 300 and $500 \mathrm{hPa}$ is defined as the center of the warm core.

Maxima and minima are located, and gradients are evaluated using bicubic splines, which provide for higher precision than the model resolution.

Storm tracking. After a database of potential storm snapshots satisfying the above conditions is created, a trajectory analysis is performed to link these together using the following procedure:

1) For each storm snapshot, a check is performed to see if there are storms during the following 6-h time period within a distance of $400 \mathrm{~km}$.

2) If there are none, the trajectory is considered to have stopped. If there are some, the closest storm is chosen as belonging to the same trajectory as the initial storm. If there is more than one possibility, preference is given to storms that are to the west and poleward of the current location.

3) To qualify as a model storm trajectory, a trajectory must last at least 2 days, and have a maximum surface (lowest model level) wind velocity within an $8^{\circ}$ radius circle centered on the storm center greater than $17 \mathrm{~m} \mathrm{~s}^{-1}$ during at least 2 days (not necessarily consecutive).

\section{REFERENCES}

Beljaars, A. C. M., 1995: The parameterization of surface-fluxes in large-scale models under free convection. Quart. J. Roy. Meteor. Soc., 121, 255-270.

Bell, G. D., and M. Chelliah, 2006: Leading tropical modes associated with interannual and multidecadal fluctuations in North Atlantic hurricane activity. J. Climate, 19, 590-612.

— , E. Blake, K. C. Mo, C. W. Landsea, R. Pasch, M. Chelliah, S. B. Goldenberg, and H. J. Diamond, 2006: The record breaking 2005 Atlantic hurricane season. Bull. Amer. Meteor. Soc., 87, S44-S45.
Bengtsson, L., K. Hodges, M. Esch, N. Keenlyside, L. Kornblueh, J.-J. Luo, and T. Yamagata, 2007: How may tropical cyclones change in a warmer climate? Tellus, 59A, 539-561.

Camargo, S., A. G. Barnston, and S. E. Zebiak, 2005: A statistical assessment of tropical cyclone activity in atmospheric general circulation models. Tellus, 57A, 589-604.

Castro, C. L., R. A. Pielke Sr., and G. Leoncini, 2005: Dynamical downscaling: Assessment of value retained and added using the Regional Atmospheric Modeling System (RAMS). J. Geophys. Res., 110, D05108, doi:10.1029/2004JD004721.

Emanuel, K. A., 2005a: Increasing destructiveness of tropical cyclones over the past 30 years. Nature, 436, 686-688.

—, 2005 b: Emanuel replies. Nature, 438, doi:10.1038/ nature 04427.

- 2006: Environmental influences on tropical cyclone variability and trends. Preprints, 27th Conf. on Hurricanes and Tropical Meteorology, Monterey, CA, Amer. Meteor. Soc., CD-ROM, 4C.2.

Frank, W. M., 1977: The structure and energetics of the tropical cyclone. I. Storm structure. Mon. Wea. Rev., 105, 1119-1135.

GFDL Global Atmospheric Model Development Team, 2004: The new GFDL global atmosphere and land model AM2-LM2: Evaluation with prescribed SST simulations. J. Climate, 17, 4641-4673.

Goldenberg, S. B., C. W. Landsea, A. M. Mesta-Nuñez, and W. M. Gray, 2001: The recent increase in Atlantic hurricane activity: Causes and implications. Science, 293, 474-479.

Houghton, J. T., Y. Ding, D. J. Griggs, M. Noguer, P. J. van der Linden, X. Dai, K. Maskell, and C. A. Johnson, Eds., 2001: Climate Change 2001: The Scientific Basis. Cambridge University Press, 881 pp.

Kalnay, E., and Coauthors, 1996: The NCEP/NCAR 40-Year Reanalysis Project. Bull. Amer. Meteor. Soc., $77,437-471$.

Kimball, S. K., and M. S. Mulekar, 2004: A 15-year climatology of North Atlantic tropical cyclones. Part I: Size parameters. J. Climate, 17, 3555-3575.

Knaff, J. A., and C. R. Sampson, 2006: Reanalysis of West Pacific tropical cyclone intensity 1966-1987. Preprints, 27th Conf. on Hurricanes and Tropical Meteorology, Monterey, CA, Amer. Meteor. Soc., CD-ROM, 5B.5.

Knutson, T. R., R. E. Tuleya, and Y. Kurihara, 1998: Simulated increase of hurricane intensities in a $\mathrm{CO}_{2}-$ warmed climate. Science, 279, 1018-1020. 
Kossin, J. P., K. R. Knapp, D. J. Vimont, R. J. Murnane, and B. A. Harper, 2007: A globally consistent reanalysis of hurricane variability and trends. Geophys. Res. Lett., 34, L04815, doi:10.1029/2006GL028836.

Kraft, R. H., 1961: The hurricane's central pressure and highest wind. Mar. Wea. Log, 5, 155.

Landsea, C. W., 1993: A climatology of intense (or major) Atlantic hurricanes. Mon. Wea. Rev., 121, 1703-1713.

- 2005: Hurricanes and global warming. Nature, 438, doi:10.1038/nature04477.

- , and Coauthors, 2004: The Atlantic hurricane database re-analysis project: Documentation for the 1851-1910 alterations and additions to the HURDAT database. Hurricanes and Typhoons: Past, Present and Future, R. J. Murname and K.-B. Liu, Eds., Columbia University Press, 177-221.

- B. A. Harper, K. Hoarau, and J. A. Knaff, 2006: Can we detect trends in extreme tropical cyclones? Science, 313, 452-454.

Lin, Y.-L., R. D. Farley, and H. D. Orville, 1983: Bulk parameterization of the snow field in a cloud model. J. Climate Appl. Meteor., 22, 1065-1092.

Lord, S. J., H. E. Willoughby, and J. M. Piotrowicz, 1984: Role of a parameterized ice-phase microphysics in an axisymmetric nonhydrostatic tropical cyclone model. J. Atmos. Sci., 41, 2836-2848.

Mann, M., and K. Emanuel, 2006: Atlantic hurricane trends linked to climate change. Eos, Trans. Amer. Geophys. Union, 87, 233-241.

McDonald, R. E., D. G. Bleaken, D. R. Cresswell, V. D. Pope, and C. A. Senior, 2005: Tropical storms: Representation and diagnosis in climate models and the impacts of climate change. Climate Dyn., 25, 19-36.

Mellor, G. L., and T. Yamada, 1982: Development of a turbulent closure model for geophysical fluid problems. Rev. Geophys. Space Phys., 20, 851-875.

Miguez-Macho, G., G. L. Stenchikov, and A. Robock, 2005: Regional climate simulations over North America: Interaction of local processes with improved large-scale flow. J. Climate, 18, 1227-1246.

Milly, P. C. D., and A. B. Shmakin, 2002: Global modeling of land water and energy balances. Part I: The land dynamics (LaD) model. J. Hydrometeor., 3, 283-299.

Moon, I.-J., I. Ginis, T. Hara, and B. Thomas, 2007: A physics-based parameterization of air-sea momentum flux at high wind speeds and its impact on hurricane intensity predictions. Mon. Wea. Rev., 135, 2869-2878.

Moorthi, S., and M. J. Suarez, 1992: Relaxed ArakawaSchubert: A parameterization of moist convection for general circulation models. Mon. Wea. Rev., 120, 978-1002.

Oouchi, K., J. Yoshimura, H. Yoshimura, R. Mizuta, S. Kusunoki, and A. Noda, 2006: Tropical cyclone climatology in a global-warming climate as simulated in a $20 \mathrm{~km}$-mesh global atmospheric model: Frequency and wind intensity analysis. J. Meteor. Soc. Japan, 84, 259-276.

Pauluis, O., and S. T. Garner, 2006: Sensitivity of radiative-convective equilibrium simulations to horizontal resolution. J. Atmos. Sci., 63, 1910-1923.

Santer, B. D., and Coauthors, 2005: Amplification of surface temperature trends and variability in the tropical atmosphere. Science, 309, 1551-1556.

Trenberth, K. E., and D. J. Shea, 2006: Atlantic hurricanes and natural variability in 2005. Geophys. Res. Lett., 33, L12704, doi:10.1029/2006GL026894.

Vitart, F., 2006: Seasonal forecasting of tropical storm frequency using a multi-model ensemble. Quart. J. Roy. Meteor. Soc., 132, 647-666.

— , and J. L. Anderson, 2001: Sensitivity of Atlantic tropical storm frequency to ENSO and interdecadal variability of SSTs in an ensemble of AGCM integrations. J. Climate, 14, 533-545.

— , and T. N. Stockdale, 2001: Seasonal forecasting of tropical storms using coupled GCM integrations. Mon. Wea. Rev., 129, 2521-2527.

—, J. L. Anderson, and W. F. Stern, 1997: Simulation of interannual variability of tropical storm frequency in an ensemble of GCM integrations. J. Climate, 10, 745-760.

—, D. Anderson, and T. Stockdale, 2003: Seasonal forecasting of tropical cyclone landfall over Mozambique. J. Climate, 16, 3932-3945.

von Storch, H., H. Langenberg, and E. Feser, 2000: A spectral nudging technique for dynamical downscaling purposes. Mon. Wea. Rev., 128, 3664-3673.

Weisse, R., H. von Storch, and F. Feser, 2005: Northeast Atlantic and North Sea storminess as simulated by a regional climate model 1958-2001 and comparison with observations. J. Climate, 18, 465-479. 